\title{
Newtons Laws Explain How Frisbees Fly
}

\author{
N. Landell-Mills
}

\section{ABSTRACT}

Newtonian mechanics explain the physics of how frisbees fly based on the mass-flow rate. Specifically, a frisbee flies through a mass of air each second (' $\mathrm{m} / \mathrm{dt})$ that it accelerates to a velocity downwards (' $\mathrm{dv}$ '). This action creates a downward force $($ Force $=m a=m / d t x ~ d v)$. The reaction is an 'equal \& opposite' upward force generated, which provides lift. Air goes down and the frisbee goes up. It's that simple. This is new and not the 'momentum' or 'flow turning' theory of lift $($ Force $=\mathbf{m a}=\mathbf{d}(\mathrm{mv}) / \mathrm{dt})$.

So what? This approach provides a simple explanation of flight consistent with what is observed in reality. It also provides new insight into lift and flight not currently found in accepted physics textbooks. For example, this insight emphasizes the importance of the Coanda effect on the top-side of the disc. Newtons laws can explain why a frisbee thrown flat (small AOA) generates better lift and will fly further than a frisbee thrown high, on a parabolic type of path. This explanation of lift can also be applied to all objects that fly, including airplanes.

Keywords: Aerodynamics, Coanda effect, frisbee, lift, Newton.
Published Online: July 13, 2020

ISSN: $2684-4451$

DOI : 10.24018/ejphysics.2020.2.4.9

N. Landell-Mills *

Independent researcher.

(e-mail: nicklm@gmx.com)

*Corresponding Author

\section{INTRODUCTION}

\section{A. Newtonian mechanics explains lift}

In short, Newtonian mechanics based on the mass-flow rate $($ Force $=\mathrm{ma}=\mathrm{m} / \mathrm{dt} \mathrm{xdv}$ ) focuses on the forces created by the wing (disc) airflows. A frisbee in horizontal flight with a positive angle of attack (AOA), will fly through a static mass of air each second (' $\mathrm{m} / \mathrm{dt}$ ) that it accelerates to a velocity ('dv') downwards. This action creates a downward force $($ Force $=m a=m / d t x d v)$. The equal and opposite upward force provides lift. See Fig. 1a.

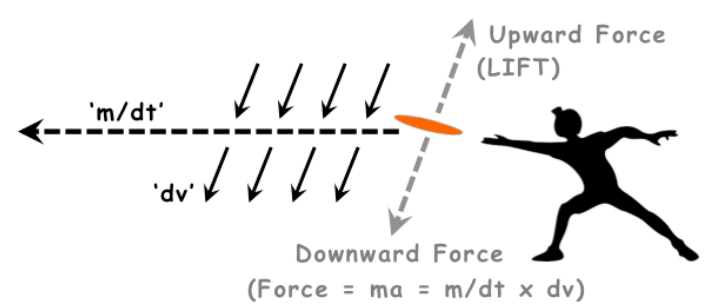

Fig. 1a. Forces and airflows on a frisbee.

More precisely, the underside of the frisbee pushes the air below the frisbee downwards. While the curved topside of the frisbee pulls the air above the frisbee downwards, helped by the Coanda effect. The Coanda effect is critical to understanding the forces involved.
For example, the best performing frisbee will be one that maximizes the Coanda effect on the topside of the disc, due to the frisbee's design or trajectory in flight. The Coanda effect increase the amount of air displaced down and thus the lift generated.

The spin on a frisbee enhances the stability of flight due to the gyroscopic effects. In turn, stability of flight allows the frisbee to generate laminar (smooth) airflows, and thus better lift. The spin itself does not directly contribute towards lift. In addition, airflow vortices account for trick throws, where the frisbee appears to defy normal physics.

\section{B. Theory of lift}

Strangely, the physics of lift is debated and unresolved. There is no realistic experiment that proves any theory or equation for lift to be true.

Newtonian mechanics based on the mass-flow rate provides a new explanation of lift that is very different to other theories based on fluid mechanics (e.g. Bernoulli and Navier-Stokes equations) and vortices (e.g. leading edge vortices). This Newtonian approach provides a simple and easily understandable explanation that fits with what is observed in reality. 


\section{Newtonian Mechanics Explains Lift}

\section{A. Lift explained using the mass-flow rate}

The theory of lift based on Newtons laws of motion provides a simple and easy to understand explanation of what is observed in reality. In summary, the frisbee with a positive angle of attack (AOA) pushes air down, the equal \& opposite force pushes the frisbee up. Note that the frisbee also pushes the air slightly forwards. See Fig. 2a.

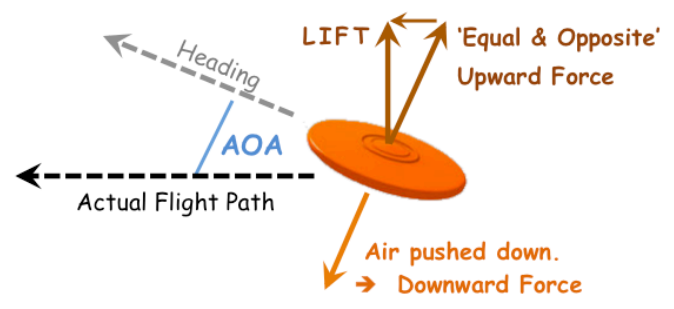

Fig. 2a. The key forces on a frisbee.

Frisbees have two separate airflows:

(i) The underside of the wing physically PUSHES the lower air mass downwards; creating high air pressure under the frisbee (Pressure $=$ Force $\mathrm{x}$ Area [1]).

(ii) As the frisbee moves forwards, the curved topside of the frisbee creates a vacuum or area of low air pressure, which PULLS the air above the frisbee downwards. This process is helped by the Coanda effect. See Fig. 2 b.

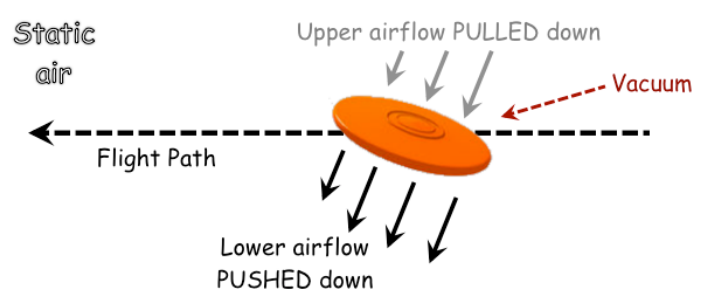

Fig. 2b. The two airflows on a frisbee.

Newtonian mechanics can be applied to explain the consequences of these two airflows that are created. In short, the frisbee flies through a mass of static air each second ('m/dt') that it accelerates to a velocity (' $\mathrm{dv}$ ') downwards. This action creates a downward force (Force $=\mathrm{ma}=\mathrm{m} / \mathrm{dt} \mathrm{x}$ $\mathrm{dv}$ ); according to Newtons 2nd law of motion [1]. The reaction generated is an 'equal and opposite' upward force, according to Newtons 3rd law of motion [1]. Lift is the vertical component of this upward force. See Fig. 2c.

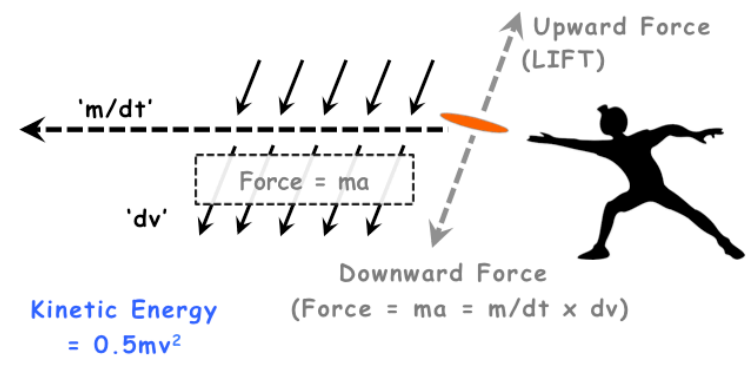

Fig. 2c. Newtonian forces on a frisbee described.
These forces are summarized by the two equations:

$$
\begin{aligned}
& \text { Downward Force }=m a=m / d t x d v \\
& \text { Downward Force }=\text { Upward Force (Lift) }
\end{aligned}
$$

Where:

$$
\begin{array}{ll}
\text { - } & \mathrm{m}=\text { mass of static air directly flown through. } \\
\text { - } & \mathrm{a}=\mathrm{dv} / \mathrm{dt}=\text { acceleration } \\
\text { - } & \mathrm{dt}=\text { change in time (per second). } \\
\text { - } & \mathrm{dv}=\text { change in velocity of the air. } \\
& \mathrm{v}=\text { velocity of the air displaced down. }
\end{array}
$$

The Newtonian explanation of lift is consistent with the key principles in physics. There is no net gain or loss of momentum, mass or energy. Momentum and energy are transferred from the frisbee to the air, to generate lift, by pushing the air down. Air goes down while the frisbee goes up and slows down.

\section{B. Newtonian mechanics and the AOA}

The angle-of-attack (AOA) will affect both ' $\mathrm{m} / \mathrm{dt}$ ' and ' $\mathrm{dv}$ ' is different ways [11]: (See Fig. 2d.)

(i) In flight frisbees have a constant wingspan exposed to the direction of flight that 'catches' air, irrespective of the AOA. The wingspan will equal the diameter of the frisbee.

(ii) A frisbee flown flat with a small AOA will catch less air each meter flown but will be able to fly faster (as there's less drag), so can 'catch' more air each second ('m/dt').

(iii) Also, a low AOA will expose less disc depth (chord) to the air flown through, so will displace air down less fast (lower ' $d v '$ '); But conversely, if the frisbee is flying faster a this low AOA, then the frisbee could accelerate the air down more aggressively.

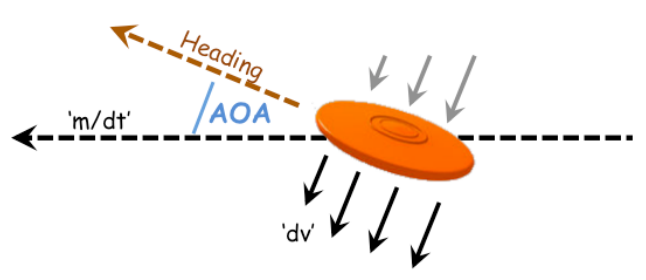

Fig 2d. AOA, 'm/dt and 'dv'.

\section{Wing (disc) area}

The wing (disc) area of the frisbee directly affects both how much air mass is flown through and displaced down (' $\mathrm{m} / \mathrm{dt}$ '), and how fast this air is accelerated to (' $\mathrm{dv}$ ') [unpublished 11]:

(i) A wider wingspan (disc) area exposed to the direction of flight increases the amount of air caught each second ('m/dt').

(ii) Wing (disc) depth (chord) primarily affects the speed that air is accelerated down ('dv'). See Fig. 2 e.

Note that as a frisbees are circular, the wingspan equals wing depth. 


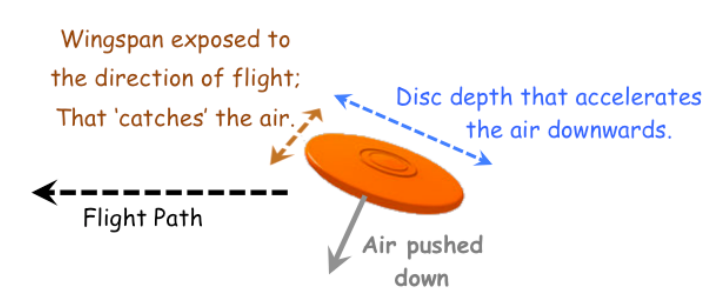

Fig, 2e Wingspan and disc depth.

\section{The Coanda effect on frisbees}

The Coanda effect has a significant impact on the physics of lift for frisbees. Fluid flow (airflow) naturally follows a curved surface due to the Coanda effect. For example, air flowing around the curved topside of a frisbee is similar to how falling water is re-directed by a spoon. See Fig. $2 \mathrm{f}$ and $2 \mathrm{~g}$.

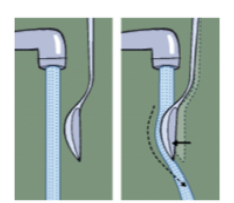

Fig. 2f. Falling water being re-directed by a spoon.

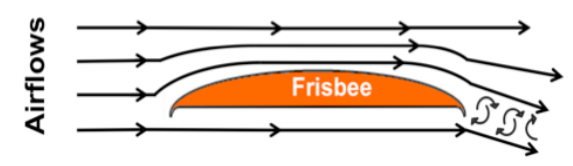

Fig. 2g. Illustration of the Coanda effect on a frisbee.

In general, frisbees produce a stronger Coanda effect at lower AOA and higher airspeeds; Also in these circumstances turbulence tends to be least. A stronger Coanda effect primarily maximizes the mass of air displaced downwards each second (' $\mathrm{m} / \mathrm{dt}$ ) and thus the lift.

The amount of air re-directed by the Coanda effect also depends on the maintenance of laminar (smooth) airflow. In turn this depends mostly on the angle-of attack (AOA) and shape of the frisbee and stability of the disc in flight. Frisbees' curved top-side provides minimal turbulence and maximizes the amount of air displaced (' $\mathrm{m} / \mathrm{dt}$ ').

\section{E. The Coanda effect on airplane wings}

As there is a lack of appropriate data and wind tunnel experiments available for frisbees, airplane wings are used as a proxy to demonstrate the Coanda effect (see Fig. 2h), as well as laminar and turbulent airflow (see Fig. 2i).
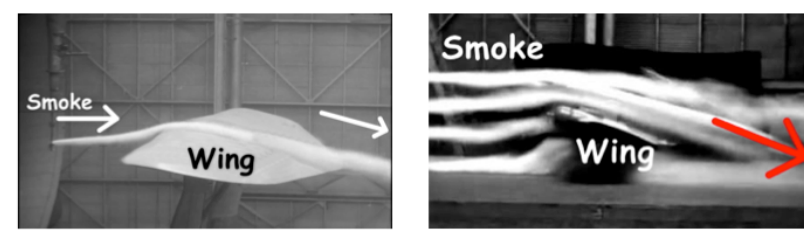

Fig. 2h. Coanda effect on airplane wings in wind tunnels. [5]
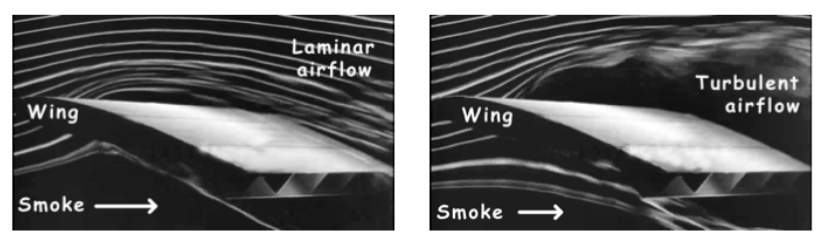

Fig. 2i. Wind tunnel; laminar and turbulent airflows. [5]

\section{F. Kinetic energy}

This application of Newtonian mechanics is consistent with the equation for kinetic energy as they use the same parameters. This means that it is possible to calculate the kinetic energy used by a frisbee to fly (See Fig. 2j):

$$
\text { Kinetic Energy }=0.5 m v^{2} \quad[1]
$$

Where:

$\mathrm{m}=$ Mass of air flown through and displaced down.

$\mathrm{v}=$ Velocity of the air displaced downwards.

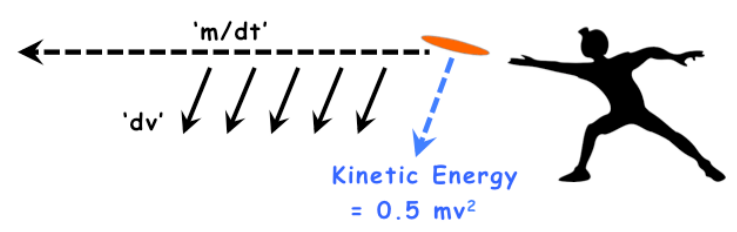

Fig. 2j. Kinetic energy for lift.

For example, a standard frisbee flying through $0.132 \mathrm{~kg}$ of air (' $\mathrm{m}$ ') each second that it displaces downwards at a velocity of $1 \mathrm{~m} / \mathrm{s}$ or about $3.6 \mathrm{~km} / \mathrm{hr}$ ('v'), would use 0.066 $\mathrm{J}$; as shown by the calculation:

$$
\text { K.E. }=0.5 \mathrm{mv}^{2}=0.5 \times 0.132 \mathrm{~kg} \times 1^{2} \mathrm{~m} / \mathrm{s}=0.066 \mathrm{~J}
$$

In contrast, it is not possible to estimate the kinetic energy required to fly using fluid mechanics.

\section{G. Spin on a frisbee}

The spin on a frisbee enhances the stability of flight due to the gyroscopic effects of the spin. In turn, stability of flight allows the frisbee to generate lift effectively by maintaining laminar (non-turbulent) airflows as much as possible. See Fig 2k.

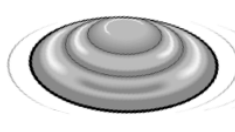

Fig. 2k. Spin on a frisbee. [5]

The frisbee's spin itself does not directly enhance vertical lift. However, spin could also help create vortices or a Magnus effect to create secondary force for trick shots. This aspect is not material to lift. 


\section{OTHER THEORIES OF LIFT}

\section{A. Newtonian mechanics}

This Newtonian explanation of lift based on the massflow rate is consistent with similar explanations for other objects generate lift by pushing air downwards: (see Fig. 3a):

1. Airplanes. [unpublished 10]

2. Helicopters. [unpublished 7]

3. Birds. [unpublished 12]

4. Insects. [unpublished 13]

5. Flying snakes. [unpublished 14]

6. Flying Squirrels. [unpublished 15]

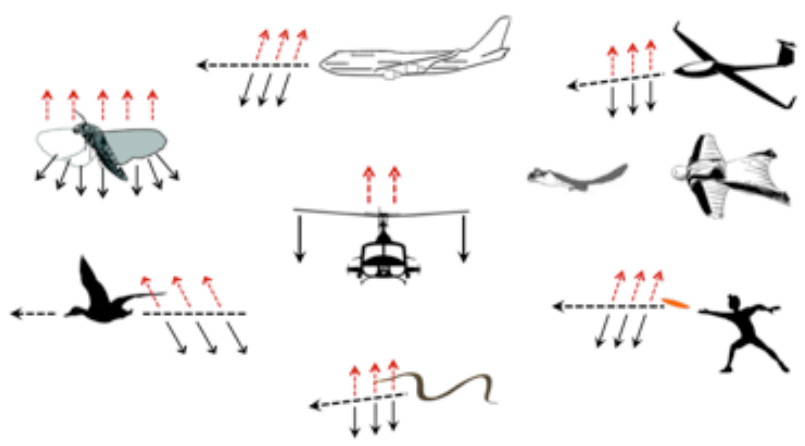

Fig. 3a. Newtonian mechanics applied to other objects.

\section{B. This is not the momentum theory of lift.}

This Newtonian explanation of lift based on the massflow rate is similar to the 'momentum' or 'flow turning' theories of lift. [1] But it is different in important ways. For example, the momentum theory of lift focuses on the change in the momentum of the air deflected downwards: Force $=$ $\mathbf{m a}=\mathbf{d}(\mathbf{m v}) / \mathbf{d t}[1]$. Whereas this paper focuses on the downward force created by the mass flow rate \& the acceleration of the air: Force $=\mathbf{m a}=\mathbf{m} / \mathbf{d t} \mathbf{x} \mathbf{d v}$.

\section{Similar Newtonian explanations of lift.}

For reference, this concept of lift based on Newtons laws of motion, is similar to that provided by the book 'Understanding Flight': "In the simplest form, lift is generated by the wing diverting air down, creating the downwash." [2]. "From Newton's second law, one can state the relationship between the lift on a wing and its downwash: The lift of a wing is proportional to the amount of air diverted (down) per time times the vertical velocity of that air." [2]. ie. Lift $=$ Downward Force $=$ ma.

The book: "Stick and Rudder" by Wolfgang Langeweische (1944) [3], which is famous among pilots for its accurate, practical and common-sense advice on how to fly a plane well. In Chapter 1 the book states: " The main fact of heavier-than-air-flight is this: the wing keeps the plane up by pushing air down. It shoves air down with the bottom surface, and it pulls air down with the top surface. But the really important thing to understand is that the wing, in whatever fashion, makes air go down. In exerting a downward force on the air, the wing receives an upward counterforce - by the same principle, known as Newton's law of action and reaction, ...." as well as: "That's what keeps a plane up. Newton's law says that if the wing pushes the air down, the air must push the wing up."

So, applying Newtons laws to explain lift is not a new idea. But using Newtonian mechanics based on the massflow rate $($ Force $=\mathrm{m} / \mathrm{dt} \mathrm{x} \mathrm{dv})$, has not been done before.

\section{The physics of lift are debated. [unpublished 8]}

Strangely, the physics of lift remains debated due to the lack of any conclusive evidence and realistic experiment to support any one theory or equation. Broadly, there are two competing theories for lift:

(i) One camp claims that fluid flow over the topside of the frisbee sucks (pulls) it upwards. This is usually based on fluid mechanics (e.g. Bernoulli, Navier-Stokes or similar complex equations). See Fig. $3 b$.
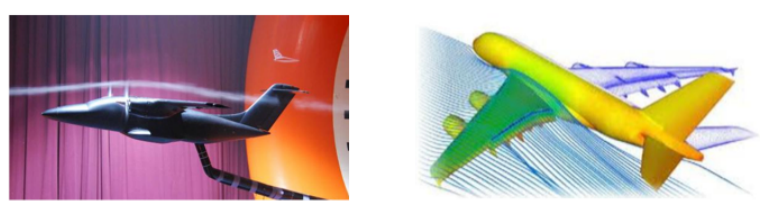

Fig. 3b. Fluid mechanics; wind tunnels \& CFD.

(ii) The other camp claims that lift is the equal and opposite force resulting from the frisbee pushing air downwards, based on Newtons laws of motion. Newtonian mechanics provide universal and fundamental laws that explain the physics of how objects move. Using the massflow rate is a new approach.

Academics, engineers, pilots aviation authorities, and other pundits (e.g. NASA) promote at least twelve radically different theories of flight. New theories are regularly proposed. In more detail:

- Academics \& engineers appear to prefer complex models and frequently confuse mathematical proof or computer simulations (e.g. CFD) for scientific proof for a particular theory.

- Aircraft manufacturers appear to design wings by intuition, trial and error, not by any particular theory or equation for lift.

- Pilots are taught to fly not by any underlying theory of lift, but by rote; "pull the stick and the airplane goes up." Principles of physics are rarely used to explain the dynamics of lift to pilots.

- It is noteworthy that NASA sits on the fence in this debate, and supports both explanations of lift. "So both Bernoulli and Newton are correct." [1] How can NASA not know which theory of flight is correct?

Worse, there is no accepted universal theory of flight that easily explains how all animals and objects fly. At present airplanes, helicopters, birds and insects each have their own unique explanations for how they stay airborne. 


\section{Newton Applied to FrisbeES}

\section{A. Frisbee trajectories}

Frisbees typically have a curved trajectory, where the lift and airspeed degrades at an exponential-like rate. See Fig. $4 \mathrm{a}, 4 \mathrm{~b}$ and $4 \mathrm{c}$.

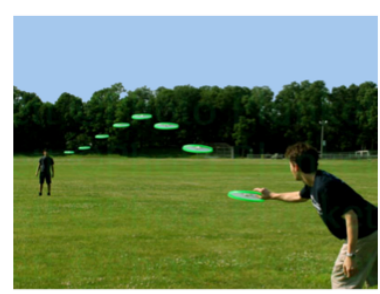

Fig 4a. Typical frisbee trajectory.

Newtonian mechanics helps explain why frisbees fly further, when thrown fast/hard and almost flat (parallel to the ground), compared to when thrown at a higher angle upwards. The reasons for this include: (See Fig. 4b.)

When thrown on a flat trajectory, the force from the throw itself is used to provide forward motion for the frisbee, and thus high airspeed, which is converted into lift by pushing the air flown through downwards.

At a low angles-of-attack (AOA) to the Coanda effect is greatest and laminar (smooth) airflow is best; displacing a lot of air downwards.

A low AOA also minimizes the drag from air resistance to flight.

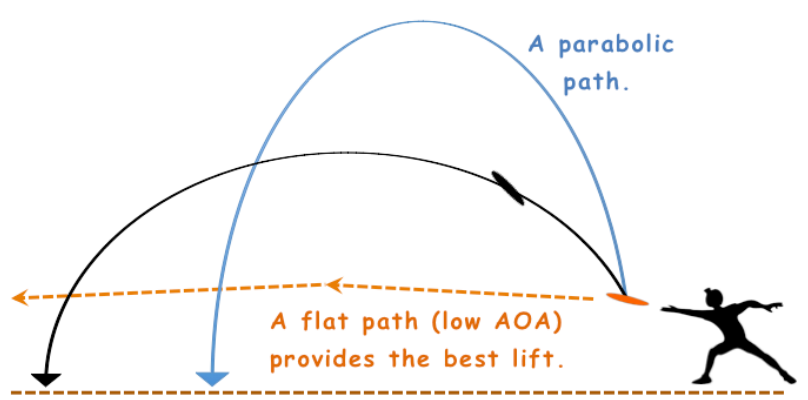

Fig. 4b. Different frisbee trajectories.

Conversely, a frisbee thrown at a very high AOA will produce high drag, weak Coanda effect on the topside of the disc, and more turbulent airflows. See Fig. 4 b.

A frisbee thrown at a very high angle upwards, on a parabolic type of path, doesn't fly very far. Most of the force of the throw is used to directly generate lift at the expense of the distance flown. See Fig. $4 \mathrm{~b}$.

\section{B. Inverted flight and hammer throws}

According to this Newtonian explanation of frisbee flight; A frisbee can fly inverted as long as it has a positive AOA to the direction of flight and displaces enough air downwards. Albeit, it won't fly as well as the curved side of the frisbee will be facing down, which will reverse the Coanda effect. When inverted, the Coanda effect will push air up instead of down, reducing the amount of lift generated.
For example, a 'hammer' throw is when the frisbee is thrown at high speed, inverted on a high parabolic type of path. Here the Coanda effect will reduce the lift generated on the upward section, and accelerate the downward speed on the downward section. Which is why it can really hurt to catch a hammer throw; the frisbees is descending a lot faster than normal, because the Coanda effect is pushing it downwards (and gravity is pulling the frisbee down from a big height too). See Fig. 4c.

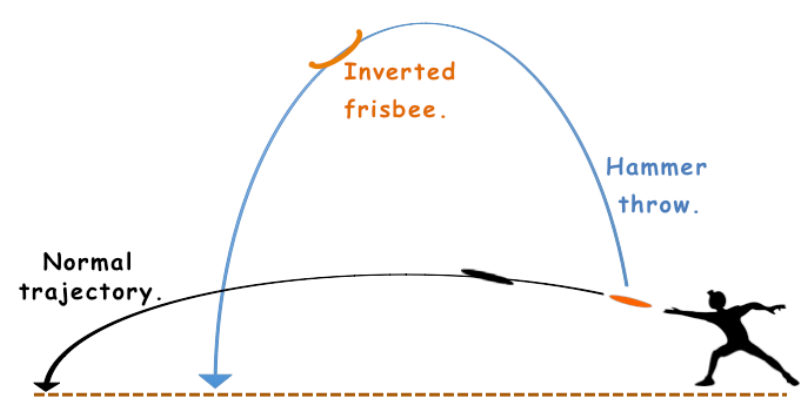

Fig. 4c. Hammer throw (inverted flight).

\section{Vortices}

The airflows around frisbees include vortices. This paper does not consider vortices to be a fundamental cause for lift and does not analyse them in detail. See Fig. 4d.

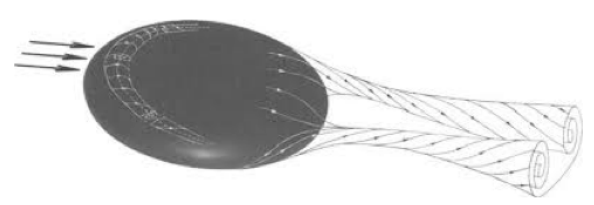

Fig. 4d. Frisbee airflows include vortices.

Although vortices and other factor like the Magnus effect can help explain many 'trick' frisbee throws. See Fig 4e.

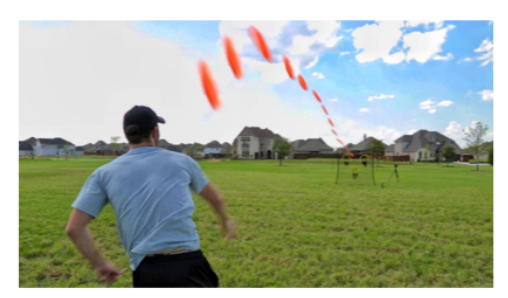

Fig. 4e. Frisbee trick shot. [4]

Vortices are complicated. For example, birds [unpublished 12] and delta wing jets are thought to use leading edge vortices to allow for flight at unusually high angles of attack. Vortices can work both ways, either boosting lift or detracting from lift, depending on the circumstances and the airflows generated. 


\section{The Standard TeXtbook Equation for Lift}

\section{A. Newton explains the standard equation for lift}

This application of Newtonian mechanics based on the mass-flow rate is also consistent with and can explain the standard equation for lift: [1]

$$
\text { Lift } \left.=0.5 \text { Velocity }^{2} \times \rho x \text { Wing Area } x C_{L}\right)
$$

Where:

Velocity $=$ Airspeed of the frisbee.

$\rho=$ Air Density.

Wing Area $=$ Disc area of the frisbee.

$\mathrm{C}_{\mathrm{L}}=$ Coefficient of lift.

Note that this equation is purely descriptive of what is observed in reality, it does not explain the relationships. Newtonian mechanics is required for the explanation. Also, this standard equation includes a coefficient of lift, which is a dimensionless parameter that cannot be directly measured or observed.

All the parameters of this standard equation for lift (aircraft velocity, air density, wing area and the lift coefficient) affect the mass of air flown through each second (' $\mathrm{m} / \mathrm{dt}$ '), as well as the velocity to which this air is accelerated downwards ('dv') [unpublished 6]. This is consistent with Newtonian mechanic's explanation of lift based on the mass flow rate:

$$
\begin{aligned}
\text { Downward Force } & =\mathrm{m} / \mathrm{dt} \times \mathrm{dv} \\
& =\text { Upward Force (lift) }
\end{aligned}
$$

\section{B. Lift $\Leftrightarrow$ Frisbee Velocity ${ }^{2}$ [unpublished 6]}

According to the standard textbook equation for lift above; vertical lift is proportional to the square of the frisbee's horizontal velocity (lift $\Leftrightarrow$ velocity $^{2}$ ). So a frisbee thrown twice as fast, will generate four times the lift (assuming all else remains constant). This has been a conundrum that no other theory of lift has been able to explain, given that lift and velocity are in different directions (vertical \& horizontal planes).

$$
\begin{array}{ccc}
\text { Lift } \\
\text { (Vertical) }
\end{array} \quad \Leftrightarrow \quad \begin{gathered}
\text { Frisbee Velocity } \\
\text { (Horizontal) }
\end{gathered}
$$

Again, Newtonian mechanics based on the mass-flow rate can explain this relationship using the example of a frisbee that is thrown twice as fast to generate four times the lift:

- First, as the frisbee's velocity doubles, then it will travel through and displace downwards twice the mass of air each second as before ( $2 \mathrm{x}$ ' $\mathrm{m} / \mathrm{dt}$ ').

- Secondly, as the frisbees velocity has doubled, then its momentum will also double $(2 \mathrm{x}$ momentum $=$ $\mathrm{m} 2 \mathrm{v})$. This means that the frisbee hits each molecule with twice the velocity and momentum as before. Consequently, each $1 \mathrm{~kg}$ of air affected by the frisbee, will be accelerated downwards to twice the velocity as before ( $2 \mathrm{x}$ ' $\mathrm{dv}$ ') .

Combining the two effects will quadruple the downward force, and thus quadruple the upward force (and the lift generated), as shown by the equations: (See Fig. 5a.)

$$
\begin{aligned}
4 \mathrm{x} \text { Downward Force } & =2(\mathrm{~m} / \mathrm{dt}) \times 2 \mathrm{dv} \\
& \Rightarrow 4 \mathrm{x} \text { Upward Force (Lift) }
\end{aligned}
$$

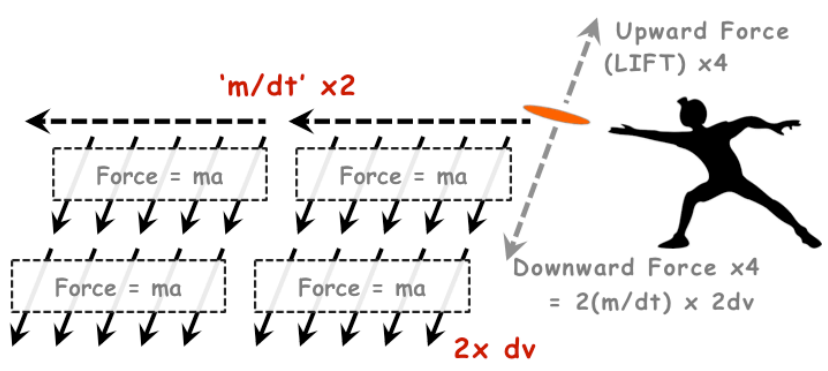

Fig. 5a. Lift $\Leftrightarrow$ Frisbee velocity ${ }^{2}$.

In summary, a frisbee travelling twice as fast will fly through twice the mass of air each second ( $2 \mathrm{x}$ ' $\mathrm{m} / \mathrm{dt}$ '), which it accelerates downwards to twice the velocity as before $(2 \mathrm{x}$ ' $d v ')$. The combined effect is to quadruple the downward force (Force $\times 4=2 \mathrm{~m} / \mathrm{dt} \times 2 \mathrm{dv}$ ), and thus quadruple both the upward force $\&$ lift generated.

\section{Standard equation re-stated [unpublished 6]}

This analysis allows the standard equation for lift to be restated into two parts; to broadly correlate with the two Newtonian parameters of the 'm/dt' and 'dv' (See Fig. 5b):

$$
\begin{aligned}
& \text { Lift }=0.5\left(\text { Velocity }^{2} \times \rho \times \text { Wing Area } \times C_{L}\right) \\
& \Rightarrow \text { Lift }=(\text { Velocity } \times \rho \times \text { Wing Area }) \\
& \quad \times\left(0.5 \times \text { Velocity } \times C_{L}\right) \\
& \Rightarrow \text { Lift }=\mathrm{m} / \mathrm{dt} \times \mathrm{dv}
\end{aligned}
$$

Therefore:

$$
\begin{aligned}
& \text { ' } \mathrm{m} / \mathrm{dt} \text { ' = (Velocity } \mathrm{x} \text { Air Density } \mathrm{x} \text { Wing Area) } \\
& { }^{\prime} \mathrm{dv} v^{\prime}=\left(0.5 \times \text { Velocity } \times C_{L}\right)
\end{aligned}
$$

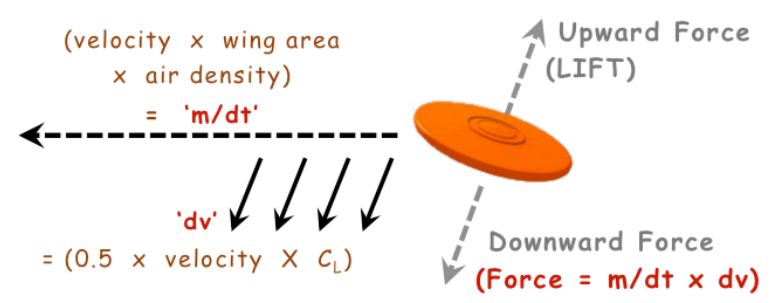

Fig. 5b. Newton applied to the standard lift equation.

The analysis in this sub-section V.C re-stating the standard equation for lift is only indicative. More work is needed for confirm that this is accurate. 


\section{BuOyancy in Flight [UnPublished 9]}

\section{A. Buoyancy defined}

A definition of buoyancy: "Archimedes Principle states that the buoyant force on a submerged object is equal to the weight of the fluid that is displaced by the object." [1]

In equilibrium (stable flight), the forces, weights and masses involved will be in balance:

$$
\begin{aligned}
& \text { Force }_{\text {DOWN }}=\text { Force }_{\mathrm{UP}}(\mathrm{Lift}) \\
& \text { Weight AIR PUSHED DOWN }=\text { Weight BALLOON UP } \\
& \Rightarrow \quad \text { Mass AIR PUSHEd DOWN }=\text { Mass BALloON UP } \\
& x \text { Gravity } x \text { Gravity }
\end{aligned}
$$

Gravity is a universal constant, being on both sides of this equation above, so cancels out. In turn, this means that the mass of the balloon also equals the mass of the air pushed downward. See Fig. 6 a.

These equations can be abbreviated to:

$$
\begin{aligned}
& \text { Lift } \Rightarrow \text { Mass AIR DOWN }=\text { Mass Balloon UP } \\
& \text { Or: Lift } \Rightarrow \text { Mass }
\end{aligned}
$$

Just to be clear, 'Lift $\Rightarrow$ Mass' is not meant to imply that $1 \mathrm{~N}=1 \mathrm{~kg}$.

By definition a $1 \mathrm{~N}$ downward force is sufficient to accelerate $1 \mathrm{~kg}$ of air at $1 \mathrm{~m} / \mathrm{s}^{2}$; [1] Or $1 \mathrm{~N}$ can be used to displace $1 \mathrm{~kg} / \mathrm{s}$ of static air at $1 \mathrm{~m} / \mathrm{s}$ (to overcome drag). The equal \& opposite upward force provides lift.

\section{B. Static and dynamic buoyancy.}

A distinction is made between static objects that achieve static buoyancy; and moving objects achieve dynamic buoyancy. See Fig. 6a.

- Static buoyancy occurs due to the volume of space passively occupied by an object creating a force that pushes a fluid downwards and the object up; which is what many people consider to be Archimedes principle of buoyancy.

- Whereas dynamic buoyancy is a new concept that occurs when an object creates a downward force by actively displacing a total mass of a fluid downwards each second equal to its mass.

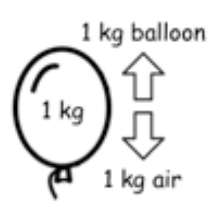

Static buoyancy

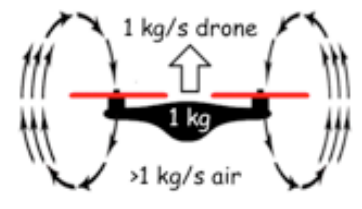

Dynamic buoyancy
Fig. 6a. Static and dynamic buoyancy.
For reference, a stationary boat achieves static buoyancy by passively displacing a mass of water equal to its mass due to the volume of space that the boat's hull occupies (Mass BOAT UP $=$ Mass WATER DOWN).

Whereas moving boats with hydrofoils can achieve dynamic buoyancy by actively displacing water downwards, enabling their hull to rise above the water. The mass of water displaced downwards each second when stationary and moving is the same. See Fig. $6 \mathrm{~b}$.

$$
\text { Lift } \Rightarrow \text { Mass WATER DOWN }=\text { Mass BOAT UP }
$$

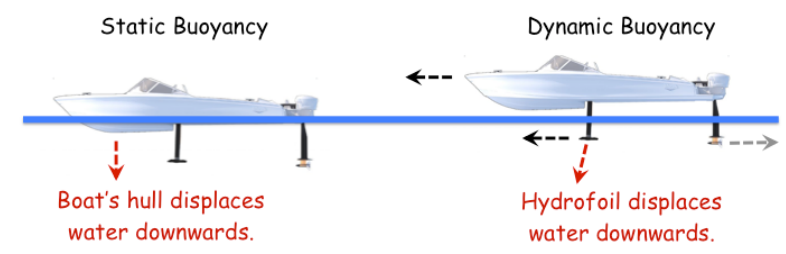

Fig. 6b. Static and dynamic buoyancy on a boat.

\section{Air is circulated in flight}

The downward force from the drone's rotors circulates a mass of air around the drone. Air pushed down with gravity, pushes air up against gravity elsewhere. So, this is a gravityneutral process and there is no net change in the atmosphere. See Fig. 6c.

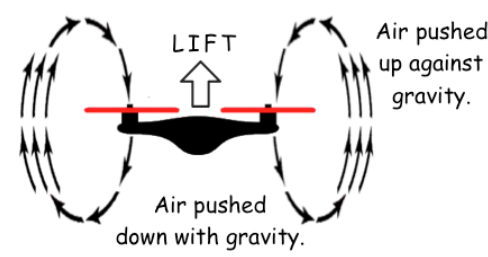

Fig. 6c. Drones circulate air in flight.

To put it another way, gravity is a universal constant and does not affect the circulation of the air. The rotors exert a force pushing air downwards, to circulate a mass of air, not a weight of air. This is shown by the equations:

$$
\begin{aligned}
& \text { Weight AIR UP }=\text { Weight AIR DOWN } \\
& \Rightarrow \quad \begin{array}{l}
\text { Mass AIR UP } \\
\text { x Gravity }
\end{array}
\end{aligned}
$$

This point is demonstrated by the thought experiment: If gravity doubled, this would not affect the force required to circulate a given mass of air.

The resistance against the downward force created by the rotors pushing air down; that then produces the 'equal \& opposite' upward force; comes from the resistance produced from the air being circulated.

To be clear, when air circulates, this does not mean that the air pushed down returns to its original position. It probably doesn't. 
Circulating a fluid to create a force is not a new concept. For example, swimmers treading water and rowing boats also achieve motion by circulating water, which is similar to helicopters. See Fig. 6d.

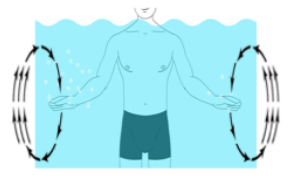

Swimmer

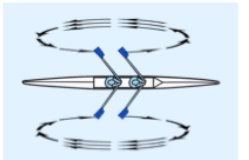

Rowing boat

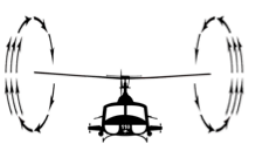

Helicopter
Fig. 6d. Things circulating fluids to generate a force.

\section{Drone-in-a-box experiments [unpublished 7]}

How much air is circulated by a drone in a hover?

Experiments have confirmed that for a helicopter drone (quadcopter) to maintain a stable hover, it only needs a force sufficient to circulate a mass of air each second, equal to its mass (not the weight of the drone, as conventional textbook physics predicts).

This assertion is based on drone-in-a-box experiments that have shown that scales below a drone at rest and a drone in a hover just above the ground, will record the same mass. Ground effect was not found to be material in these experiments. See Fig. 6e.

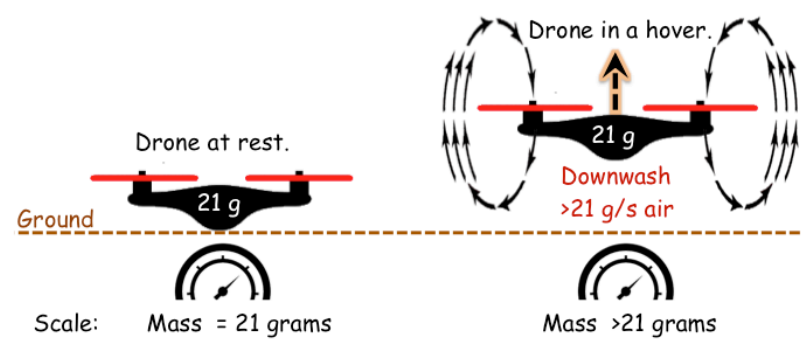

Fig. 6e. Drone at rest and in a hover.

For example, a $21 \mathrm{~g}$ helicopter drone (quadcopter) in a stable hover exerts a force that is sufficient to displace down and circulate slightly more than $21 \mathrm{~g} / \mathrm{s}$ of air. Slightly more air is circulated than the mass of the drone, as the drone is not $100 \%$ efficient as generating lift.

While it is technically correct to state that in a stable hover: the weight of the drone pushed up, will equal the weight of the air pushed down by the rotors (Weight DRONE UP $=$ Weight AIR DOwN). But the drone's rotors circulate a mass of air, not a weight of air. Gravity does not affect the amount of air circulated. It is more accurate to focus on the masses involved, rather than weights involved.

\section{E. Total mass of air displaced}

The total mass of air displaced by the drone or frisbee equals: the sum of the air directly flown through displaced down (' $\mathrm{m} / \mathrm{dt}$ '), and the air indirectly displaced by accelerating this air downwards ('dv'). See Fig. $6 f$ and $6 g$.
Where:

$\mathrm{m} / \mathrm{dt} \rightarrow$ Air DIRECTLY displaced

$\mathrm{dv} \rightarrow$ Air INDIRECTLY displaced

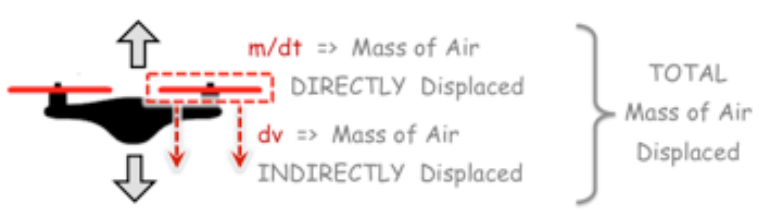

Fig. 6f. Total mass of air displaced by a drone.

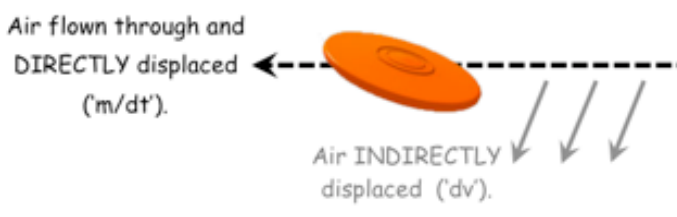

Fig. 6g. Total mass of air displaced by a frisbee.

\section{F. Summary: Lift $\Rightarrow$ Mass}

Drones can hover when the lift force is sufficient to displace down and circulate a mass of air each second that is equal to the drone's mass (not its weight).

Lift $\Rightarrow$ Mass AIR DOWN $=$ Mass DRONE UP

In a stable hover the forces, weights and masses involved are in balance. See Fig $6 g$.

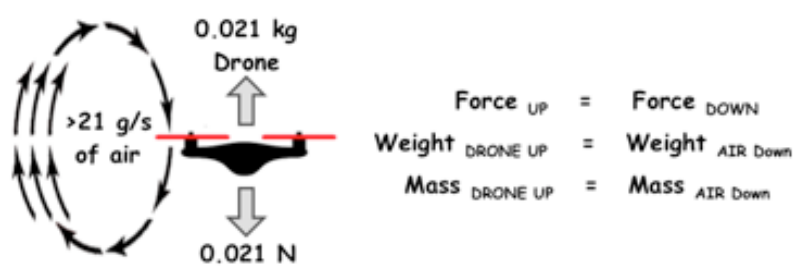

Fig. 6g. Total mass of air displaced.

Similarly, frisbees in flight will exert a downward force sufficient to displace downwards and circulate a mass of air that is equal to the mass of the frisbee. See Fig. $6 \mathrm{~h}$.

Lift $\Rightarrow$ Mass AIR DOWN $=$ Mass FRISBEE UP

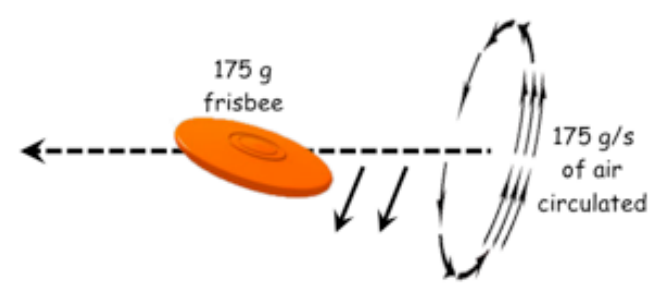

Fig. 6h. Air is circulated by a frisbee. 


\section{EXAmple CAlculation of Lift}

\section{A. Overview and assumptions}

Calculations using Newtonian mechanics below based on relatively conservative assumptions, show that it is feasible for a frisbee to generate a sufficient lift force to achieve buoyancy and fly.

This example calculation is only an approximation to demonstrate that the principles discussed in this paper can be applied to what is observed in reality. More accurate calculations based on experimentation is required.

Specifically, calculations assume: A typical frisbee that is $25 \mathrm{~cm}$ in diameter, and $175 \mathrm{~g}$ mass, is thrown at $11 \mathrm{~m} / \mathrm{s}(40$ $\mathrm{km} / \mathrm{hr}$ ), where all the air directly flown through $(2 \mathrm{~cm}$ above and below the frisbee) is accelerated down at about $1.3 \mathrm{~m} / \mathrm{s}$ (about $5 \mathrm{~km} / \mathrm{hr}$ ); to generate lift. The total mass of air displaced (directly and indirectly) down each second, and circulated, equals the mass of the frisbee. See Fig. $7 \mathrm{a}$.

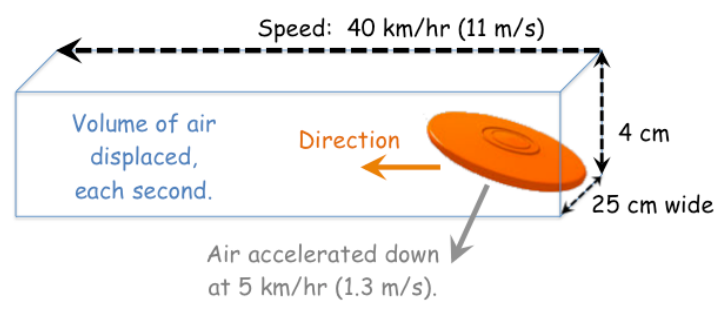

Fig. 7a. Illustration of the key assumptions.

'Wing Reach' is the average vertical distance away from the wing (disc) that the wing influences the air. A Wing Reach of $4 \mathrm{~cm}$ is assumed; this is $2 \mathrm{~cm}$ above and below the frisbee. Wing Reach depends on things like the wing shape, wing AOA and airspeed.

The average wing reach is assumed to be constant across the frisbee's diameter (so shown as a box around the frisbee). Whereas, in reality it is more likely to be elliptical in shape; as wing reach should be greater at the center of the frisbee and less at the edges.

The frisbee's velocity of $11 \mathrm{~m} / \mathrm{s}$ is about $40 \mathrm{~km} / \mathrm{hr}$; which fits with what is observed in reality. It is easily within the range of velocities that frisbees are commonly thrown.

It is assumed that the frisbee is thrown at a relatively low AOA; and all the upward force is converted into lift (ie. there's negligible induced drag from the frisbee pushing air slightly forwards).

\section{B. Methodology}

First, the volume of air directly flown thrown and displaced down each second is estimated. Then the air density is used to convert this the volume of air into the mass of air ('m/dt') 'flown' thrown and displaced down each second.
Then the vertical downward velocity of the air displaced is estimated ('dv'). This allows for a calculation of the downward force (Force $=\mathrm{ma}=\mathrm{m} / \mathrm{dt} \mathrm{x} \mathrm{dv}$ ); and thus the equal and opposite upward force (lift).

\section{Volume of air flown thrown}

First, the volume of air directly flown thrown and displaced down each second is estimated. This volume is based on the frisbee's velocity, diameter (wingspan) and the vertical distance away from the frisbee that the air is affected ('wing reach').

Volume of air flown through each second

$=($ distance thrown in one second $\mathrm{x}$ Frisbee diameter $\mathrm{x}$ Wing Reach )

$=(1100 \mathrm{~cm} / \mathrm{s} \times 25 \mathrm{~cm} \times 4 \mathrm{~cm})$

$=110,000 \mathrm{~cm}^{3} / \mathrm{s}$

$=0.11 \mathrm{~m}^{3} / \mathrm{s}$

\section{Mass of air flown through each second (' $m / d t$ ')}

The volume of air flown through each second, is converted into mass of air flown through each second using the standard density of air of $1.2 \mathrm{~kg} / \mathrm{m}^{3}$ [1].

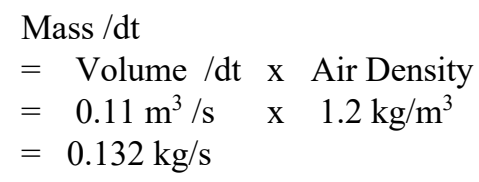

\section{E. Acceleration of the air (' $d v$ ')}

The lift force that the frisbee needs to generate to fly is the equal \& opposite upward force to the downward force.

$$
\begin{aligned}
& \text { Downward Force } \\
& \quad=\mathrm{ma} \\
& =\mathrm{m} / \mathrm{dt} \times \mathrm{dv} \\
& =0.132 \mathrm{~kg} / \mathrm{s} \text { x } 1.33 \mathrm{~m} / \mathrm{s} \\
& =0.175 \mathrm{~kg} \mathrm{~m} / \mathrm{s}^{2}=0.175 \mathrm{~N}
\end{aligned}
$$

Therefore:

$$
\begin{aligned}
& \Rightarrow \text { Lift }=\text { Downward Force }=0.175 \mathrm{~N} \\
& \Rightarrow \quad 0.175 \mathrm{~kg} / \mathrm{s} \text { total mass of air displaced down. }
\end{aligned}
$$

\section{F. Summary}

In summary, the downward force of $0.175 \mathrm{~N}$ is sufficient to displace a total mass of air (directly and indirectly) down each second of $0.175 \mathrm{~kg} / \mathrm{s}$, that equals the mass of the frisbee $(0.175 \mathrm{~kg})$. So, the frisbee will fly. See Fig. $7 \mathrm{~b}$.

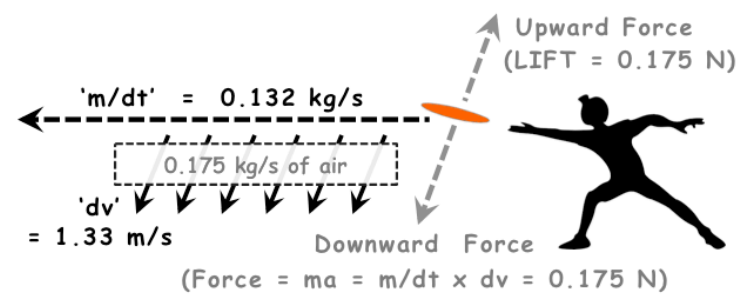

Fig. 7b. Key data summarized. 


\section{DISCUSSION OF RESUlts}

It should not be surprising that Newtonian mechanics can explain how a frisbees flies in a manner that is consistent with the standard equation for lift (Lift $=0.5 \mathrm{x}$ Velocity $2 \mathrm{x}$ Air Density x Disc Area x Lift Cf.). It would be more surprising to claim that Newtonian mechanics doesn't explain lift and how a frisbee flies.

Calculations based on relatively conservative assumptions, show that it is feasible for a frisbee to generate a sufficient lift force to achieve buoyancy and fly.

This is original analysis that provides significant new insight into how frisbees fly, which helps to resolve the debate regarding the physics of lift. This explanation is not what is currently taught by most relevant physics textbooks.

Frisbees in flight are effectively floating in the air by circulating enough air to achieve dynamic buoyancy. More experimentation needs to be done to confirm the assertions and calculations made by this paper.

\section{CONCLUSIONS}

Newtonian mechanics explains the physics of how a frisbee flies, consistent with what is observed in reality and the standard equation for lift.

\section{ACKNOwledgments}

None.

\section{REFERENCES}

[1] NASA, Glenn Research Centre. www.grc.nasa.gov

Books:

[2] D.F. Anderson and S. Eberhardt, Understanding Flight (2nd edition); 2010; McGraw-Hill; ISBN: 978-0-07- 162697-2. ch 9 pp 125;

[3] "Stick and Rudder" by Wolfgang Langeweische; 1944; ISBN 978-007-036240-6; ch. 1. pp 9.

Sources:

[4] Image source: Frisbee Target Trick Shots, Brodie Smith; https://www.youtube.com/watch?v=UbxB6Dvzf18

[5] Unknown sources. Images were available on the internet without clear acknowledgment.

Unpublished papers by the author:

[6] N. Landell-Mills (2019), Newton explains why lift is proportional to velocity ${ }^{2}$; Pre-Print DOI: 10.13140/RG.2.2.20536.70409.

[7] N. Landell-Mills (2019), Archimedes principle applied to helicopters to explain flight; Pre-Print DOI: 10.13140/RG.2.2.27096.55048;

[8] N. Landell-Mills (2019), The theory of flight remains unresolved, PrePrint DOI: 10.13140/RG.2.2.34380.36487;

[9] N. Landell-Mills (2019), Buoyancy explains how airplanes fly (summary); Pre-Print DOI: 10.13140/RG.2.2.16863.82084.

[10] N. Landell-Mills (2019), Newton explains lift using the mass-flow rate; Pre-Print DOI: 10.13140/RG.2.2.10600.01288.

[11] N. Landell-Mills (2019), Newtonian mechanics explains how wing design affects lift (glider v. fighter jet); Pre-Print DOI: 10.13140/RG.2.2.20216.80647.

[12] N. Landell-Mills (2019), Newtons laws explain how birds fly; PrePrint DOI: $10.13140 /$ RG.2.2.19558.98885

[13] N. Landell-Mills (2020), Newtons laws explain how insects fly, including bees; Pre-Print DOI: 10.13140/RG.2.2.13994.98247.

[14] N. Landell-Mills (2019), Newton explains the physics of flying snakes; Pre-Print DOI: 10.13140/RG.2.2.12719.48806.

[15] N. Landell-Mills (2020), Newtonian mechanics explains how squirrels \& wingsuits 'fly' based on the mass flow rate; Pre-Print DOI: $10.13140 /$ RG.2.2.27717.60646.

\section{AdDITIONAL INFORMATION}

The author is British and was born in 1966 in Botswana

The author is a graduate of the Dept. of Humanities \& Social Sciences, The University of Edinburgh, Edinburgh, UK. He was awarded a M.A. degree class 2:1 in economics and economic history in 1989 . He is qualified accountant (ACA) in 1993 and a chartered financial analyst (CFA) in 2006. He was a member of the HAC in the UK army reserves 1990-7; where he was trained by 22 SAS.

The author worked in finance and telecoms $1990-2012$. He has been an independent researcher since 2015, based in Chamonix, France. He was has a strong interest in the physics of flight and has written 20 papers on in this subject (4 published and 16 unpublished), which are available on www.researchgate.net. He was a private pilot (PPL) and maintained his own 'home-built' single-engine aircraft (reg: GOSJN).

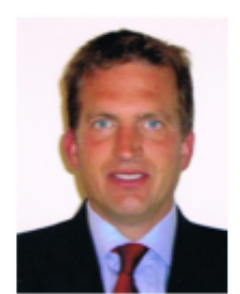

Author Contributions: This paper is entirely the work of the author, Mr. Nicholas LandellMills.

Disclaimer: The author confirms that all data in the manuscript are authentic, there are no conflicts of interest, and all sources of data used in the paper are acknowledged (except where the correct source could not be identified).

Funding: This paper was self-funded by the author. 